\title{
HUBUNGAN TIMBAL BALIK MANUSIA DAN ALAM DALAM LEGENDA IKAN BUNGO: KAJIAN EKOLOGI SASTRA
}

\author{
Arisa $^{1}$, Muhlis $^{2}$, Andi Srimularahmah ${ }^{3}$, Nur Rahmi ${ }^{4}$ \\ Universitas Puangrimaggalatung ${ }^{124}$, STKIP Muhammadiyah Bone ${ }^{2}$ \\ arisa@uniprima.ac.id ${ }^{1}$, muhlis.chaly@gmail.com ${ }^{2}$, andisrimularahmah@gmail.com ${ }^{3}$, \\ nurrahmi.sarif1@gmail.com ${ }^{4}$
}

\begin{abstract}
Literary ecology in the Bungo Fish legend discusses the relationship between humans and nature and vice versa. To create a balance, awareness is needed in managing, preserving and maintaining local wisdom, which is beginning to erode due to human unpreparedness in facing technological developments. The problems in literary works, especially the Bungo Fish legend originating from Sumpabaka in Wajo Regency, are based on several reasons. First, there is a relationship between living things and their environment experienced by the main character, namely Topanggalung and Bungo Fish. Second, the local colour is very thick in the legend of Bungo Fish, which is that the people who come from Sumpabaka do not consume Bungo Fish. Third, the problem of literary ecology in the Bungo Fish legend, if examined carefully, is social criticism of real life that does not pay attention to nature. This study discusses the reciprocal relationship between humans (characters) and nature based on literary ecology based on the problems above. This study describes the literary ecology related to the reciprocal relationship between humans and nature in the Bungo Fish legend. The method used in this research was a literature study that specifically examined the text on the Bungo Fish legend. The collected data analyzed by analytic descriptive and data analysis techniques. The results of research related to the reciprocal relationship between humans and nature include human responsibility towards nature, living in harmony with nature, being fair with nature, upholding democracy with nature, and moral integrity.

Keywords: Relationship, Human, Nature, Bungo Fish Legend, Literary Ecology.
\end{abstract}

\begin{abstract}
ABSTRAK
Ekologi sastra dalam legenda Ikan Bungo membahas hubungan manusia dengan alam begitupun sebaliknya. Untuk menciptakan keseimbangan diperlukan kesadaran dalam mengelola, melestarikan, dan mempertahankan kearifan lokal yang mulai terkikis atas ketidaksiapan manusia dalam menghadapi perkembangan teknologi. Permasalahan dalam karya sastra khususnya legenda Ikan Bungo yang berasal dari Sumpabaka di Kabupaten Wajo ini, dilandasi oleh beberapa alasan. Pertama adanya hubungan antara makhluk hidup dengan lingkungannya yang dialami oleh tokoh utama, yakni Topanggalung dengan Ikan Bungo. Kedua, warna lokal yang sangat kental dalam legenda Ikan Bungo, salah satunya masyarakat yang berasal dari Sumpabaka tidak mengkonsumsi Ikan Bungo. Ketiga, permasalahan ekologi sastra pada legenda ikan Bungo jika dikaji dengan saksama, merupakan kritik sosial terhadap kehidupan nyata yang kurang memperhatikan alam. Berdasarkan identifikasi masalah di atas, penelitian ini fokus membahas hubungan timbal balik manusia (tokoh) dengan alam berdasarkan ekologi sastra.Tujuan penelitian ini untuk mendeskripsikan ekologi sastra terkait hubungan timbal balik manusia dengan
\end{abstract}


alam dalam legenda Ikan Bungo. Metode yang digunakan dalam penelitian ini adalah metode studi pustaka yang secara khusus akan meneliti teks pada legenda Ikan Bungo. Data yang dikumpulkan akan dianalisis dengan deskriptif analitik dan tehnik analisis data. Hasil penelitian terkait hubungan timbal balik manusia dan alam meliputi tanggung jawab manusia terhadap alam, hidup selaras dengan alam, Adil dengan alam, menjunjung tinggi demokrasi dengan alam, integritas moral.

\section{Kata Kunci: Hubungan, Manusia, Alam, Legenda Ikan Bungo, Ekologi Sastra}

\section{PENDAHULUAN}

Alam dan manusia seharusnya bersinergi untuk membentuk keharmonisan agar terjadi keseimbangan hidup yang saling berkorelasi dengan menaati dan merealisasikan norma-norma berkaitan dengan kearifan lingkungan hidup. Kenyataannya, alam dan segala isinya sekadar alat kepentingan untuk memenuhi kebutuhan hidup manusia semata.

Bencana yang terjadi di Indonsia sebagian besar disebabkan oleh keserakahan manusia. Hal ini, dapat dilihat pada data bencana di Indonesia melalui Harian Kompas, Selasa, 30 April 2019. Data dirilis oleh Badan Penanggulangan Bencana (BNPB). Sebanyak 325 orang meninggal dan 113 orang hilang akibat 1.538 kejadian bencana di Indonesia, lebih dari 98 persen bencana yang terjadi adalah bencana hidrometeorologi sedangkan 2 persen bencana geologi. Bencana terbesar disebabkan oleh banjir dan longsor bahkan kerugian terbesar dialami oleh Sulawesi Selatan.

Kerusakan alam yang terjadi di bumi sebagian besar dilakukan manusia. Di era modern ini, manusia memperlakukan alam secara eksploitasif dengan tanpa mempertimbangkan akibat setelahnya. Krisis lingkungan yang terjadi tentu saja menimbulkan keresahan bagi berbagai kalangan termasuk pengarang. Pengungkapan secara ekologi dianggap mampu menjelaskan bahwa sastra merupakan produk kreatif alam di mana manusia tidak terpisahkan darinya. Dengan demikian, pesan-pesan kearifan dalam sastra akan menjangkau keseluruhan kehidupan di alam semesta.

Alam menyediakan sumber daya alam bagi makhluk hidup yang ada di bumi. Manusia sebagai salah satu penghuni alam memiliki sifat konsumtif, di mana sebagian besar manusia hanya mengkonsumi tanpa bertanggungjawab sebagaimana mestinya memperlakukan alam. Akibatnya dari sifat konsumtif membuat keadaan lingkungan semakin rusak dan mengubah ekosistem yang sudah tertata dengan tepat sehingga lambat laun manusia akan semakin kekurangan sumber daya alam di bumi ini.

Bangsa Indonesia adalah bangsa yang kaya akan kebudayaan dan kebudayaan ini mencari ciri dan pembeda dengan kebudayaan dengan negara lain. Ciri-ciri kebudayaan ini juga membedakannya dengan budaya berbagai daerah di Indonesia (Koentjaraningrat, 2009: 151).

Ekologi berasal dari kata oikos. Dalam Bahasa Yunani oikos berarti rumah atau tempat tinggal. Maksudnya tempat tinggal bagi semua perempuan dan laki-laki, hewan, tumbuhan, air, tanah, udara, dan matahari. Ekologi mempelajari hubungan antar manusia dan lingkungan hidup, mengaitkan antar ilmu kemanusiaan dan ilmu alam. Ekologi sastra merupakan salah satu ilmu interdisipliner (Sudikan, 2016: 1).

Ekologi sastra merupakan teori sastra yang membahas sastra, masyarakat, dan alam sekitarnya. Teori ini dimunculkan dalam penelitian sebagai bentuk kesadaran dalam melestarikan alam (Noni, 2019: 83). Penelitian terkait ekologi sastra dapat menstimulus dan menumbuhkan kecerdasan ekologi yang dapat menjadi solusi dalam menanggulangi bencana saat ini Suwandi (Noni dan Alber, 2019: 52).

Manusia dalam karya sastra biasanya disebut tokoh. Tokoh adalah para pelaku yang 
terdapat dalam sebuah karya fiksi (Wiyatmi, 2006: 30). Tokoh merupakan ciptaan pengarang yang dalam dunia nyata yang dapat direfleksikan. Pengarang memberikan citra tokoh kepada pembaca seperti makhluk hidup pada umumnya. Tokoh merujuk pada orang sebagai pelaku cerita (Nurgiyantoro, 2013: 247). Alam dalam lingkungan dipresentasikan oleh pengarang karya sastra dalam bentuk latar. Penggambaran latar secara baik akan memberi konteks dalam sebuah cerita, sehingga alur cerita akan jelas. Fungsi ini menjadikan latar sangat penting. Latar juga dijadikan sebagai bahan penelitian dalam cerita fiksi.

Perubahan teknologi dan kuatnya arus globalisasi perlahan menggeser nilai-nilai kearifan lokal lingkungan yang sarat akan nilai kehidupan. Kurangnya minat mempelajari karya sastra lokal semakin menjauhkan nilainilai luhur yang telah diwariskan secara turuntemurun oleh para leluhur di masa lalu Supriyadi (2020: 2). Hal ini mendorong pengarang di Indonesia untuk terus berkarya dengan mengangkat tema kearifan lokal dan lingkungan yang ada di setiap daerah.

Ketika pengarang menjabarkan suatu daerah, maka hal yang berkaitan dengan daerah tersebut juga dijabarkan sehingga sastra dapat disebut dunia miniatur. Karya sastra sebagai dunia miniatur berfungsi untuk menginvestasikan kejadian-kejadian yang telah dikerangkakan dalam pola-pola kreativitas dan imajinasi. Kejadian dalam karya sastra pada dasarnya adalah prototipe dari kejadian yang pernah atau mungkin terjadi dalam kehidupan ke dalam kualitas dunia fungsional (Endraswara, 2016: 81). Sastra sebagai prototipe cendrung menggambarkan daerah yang ditempati secara nyata.

Sastra lisan adalah sastra yang paling menonjol diantara peninggalan sastra lainnya dalam masyarakat. Sastra lisan adalah ekspresi kesusastraan warga kebudayaan yang diturunkan dan disebarkan secara lisan (Hutomo, 1991: 1).

Sastra lisan pada dasarnya adalah sastra dalam bentuk ujaran yang diceritakan dari mulut ke mulut. Selain itu, sastra merupakan kebudayaan yang diwariskan secara turun-temurun oleh masyarakat. Sama halnya yang dengan yang dikemukakan oleh (Danandjaja, 2007: 19) sastra lisan merupakan bagian dari kehidupan sastra yang memiliki posisi sangat penting dalam masyarakat. Sastra lisan memiliki banyak fungsi yang sangat penting dalam masyarakat untuk diteliti dan agar dapat diterapkan dalam pembangunan bangsa (Krisdayani, 2019: 59).

Satu diantara sastra lisan adalah legenda (Danandjaja, 2007: 66) legenda bersifat sekuler "keduniawian" terjadi pada masa yang sangat lampau dan bertempat di dunia sebagaimana dunia kita sekarang. Legenda seringkali dipandang sebagai "sejarah" kolektif dan menjadi perdebatan diberbagai kalangan karena kelisanannya mengalami distorsi.

Ciri-ciri legenda menurut (Rusyana, dkk, 2000: 38) sebagai berikut: 1) tokoh dalam legenda dibayangkan sebagai tokoh yang hidup pada masa lalu, mereka adalah orang-orang yang terkemuka dan sangat berpengaruh, misalnya Topanggalung yang merupakan raja di Sumpabaka. 2) Tokoh pendukung lainnya juga orang yang dihormati yang terlibat dalam membangun kesejahteraan masyarakat. 3) Para pelaku dianggap sebagai pelaku sejarah pada masa dan tempat tertentu yang memiliki andil besar dalam masyarakat. 4) Latar cerita biasanya terjadi di sungai. 5) Waktu terjadinya peristiwa adalah pada masa lalu namun bukan masa purba. 6) Pelaku dan peristiwa dibayangkan benar-benar terjadi seolah peristiwa dalam legenda tersebut adalah kisah nyata.

Berdasarkan ciri-ciri legenda di atas legenda yang diteliti dalam penelitian ini mengenai Legenda Ikan Bungo. Legenda Ikan Bungo ini menjadi awal mula masyarakat yang tinggal di Sumpabaka Kabupaten Wajo Sulawesi Selatan tidak mengkonsumsi Ikan Bungo hingga hari ini.

Dalam legenda Ikan Bungo, sosok Topanggalung awalnya marah dan merusak alam sehingga hutan, hewan, dan tumbuhan lainnya mengalami kerusakan yang akibatnya berdampak pada kebutuhan hidup manusia. Kesepakatan antara Buriq Liu (Dunia Bawah) 
dan Allekawa (Dunia Tengah) memberikan dampak positif yang bernilai baik seperti menepati janji, bertanggung jawab, tidak membeda-bedakan jenis maupun tingkat sosial, dan musyawarah untuk mufakat dalam menyelesaikan segala permasalahan antara dunia Bawah dan dunia Tengah.

Menurut Taum (2011: 6) dua alasan manusia mendalami dan menggiati sastra 1) manusia memiliki insting meniru. Hal ini dapat dijadikan contoh dalam kehidupan bermasyarakat. Sejak masa kanak-kanaknya manusia suka meniru. 2) Fakta adanya gejala universal bahwa ketika melakukan peniruan tersebut, manusia merasakan sensasi-sensasi yang indah dan menyenangkan. Berdasarkan sifat manusia yang suka meniru, maka penelitian terkait hubungan timbal balik manusia dan alam dalam legenda Ikan Bungo ini dapat dipedomani sebagai peninggalan leluhur dengan tujuan agar manusia belajar dan bersinergi dengan lingkungan sehingga terjadi keselarasan dan kedamaian.

Berdasarkan permasalahan yang pada latar belakang penelitian, peneliti tertarik untuk mengkaji Hubungan Timbal Balik Manusia dan Alam dalam Legenda Ikan Bunga: Kajian Ekologi Sastra.

\section{METODOLOGI PENELITIAN}

Penelitian ini adalah penelitian kualitatif. Penelitian kualitatif adalah penelitian yang naturalistik artinya penelitian ini dilakukan dengan kondisi alamiah (Sugiyono, 2012: 14) dengan menggunakan metode deskriptif.

Metode deskriptif digunakan untuk mendeskripsikan hubungan timbal balik manusia dan alam dalam legenda Ikan Bungo. Sumber data berasal dari cerita Legenda Ikan Bungo, objek penelitian berupa ekologi sastra terkait hubungan timbal balik manusia dan alam. Teknik pengumpulan data dengan teknik pustaka. Teknik pustaka adalah teknik yang menggunakan sumber-sumber tertulis untuk memperoleh data (Subroto, 2007: 172) dengan cara membaca, menandai, mengklasifikasi data yang berhubungan dengan hubungan timbal balik manusia dan alam. Peneliti melakukan analisis data, pemberian interpretasi, dan melakukan deskripsi bagian demi bagian yang ditemukan dalam penelitian.

\section{HASIL DAN PEMBAHASAN}

Penelitian yang relevan dengan penelitian ini cukup banyak dilakukan, hanya saja lebih banyak membahas tentang ekologi yang menekankan aspek alam sebagai inspirasi karya sastra, ekologi yang menekankan pembelaan atau advokasi terhadap kerusakan lingkungan yang disebabkan oleh perbuatan manusia atau dikenal dengan ekokritik sastra, dan penelitian tentang ekofeminisme yang membahasa perempuan, alam dan lingkungannya.

Agtasia Ferdan (2019) Etika Lingkungan dalam Novel Bilangan Fu Karya Ayu Utami dan Implikasinya pada Pembelajaran Sastra di Sekolah hanya menjabarkan etika-etika lingkungan.

Moh. Badrus Solichin (2019) Ketika Alam dan Perempuan Lembah Belien Diperkosa oleh Antroposentrisme Kapitalis Kajian Ekofeminisme dalam Novel Tanah Tabu dengan temuan penelitian kekerasan terhadap perempuan, budaya patriarki, dan eksploitasi terhadap alam.

Penelitian Ulfa Widayati (2018) Representasi Budaya Masyarakat Dayak Meratus dalam Novel Palas Karya Aliman Syahrani dan Implikasinya Bagi Pendidikan Karakter Siswa SMA (Kajian Etnoekologi Sastra) dengan hasil temuan bentuk sistem ide, sistem aktivitas, benda budaya dan konstruksi tentang Pendidikan karakter pada novel Palas karya Aliman Syahrani.

Penelitian relevan menggunakan kajian ekologi sastra, etnoekologi sastra dan ekokritik sastra dan implikasinya di sekolah dan tidak fokus mengkaji hubungan timbal balik manusia dan alam khususnya dalam cerita legenda lokal.

Hasil penelitian yang diperoleh dalam Legenda Ikan Bungo adalah tanggung jawab, hidup selaras dengan alam, adil dengan alam, musyawarah dan mufakat, dan integritas moral.

\section{Tanggung Jawab}

Tema dalam Legenda Ikan Bungo mengenai Sumpah Topanggalung dengan Ikan 
Bungo tentang "Siri na Tanro" atau dalam kamus besar bahasa Indonesia "siri" berarti sistem nilai sosiokultural kepribadian yang merupakan pranata harga diri dan martabat manusia sebagai individu dan anggota masyarakat Bugis sedangkan "tanro" berarti sumpah atau pernyataan yang disertai tekad melakukan sesuatu untuk menguatkan kebenarannya atau berani menderita sesuatu kala pernyataan itu tidak benar. Di dalam istilah lain "tanro" juga bisa dikatakan sebagai janji atau ikrar yang teguh (akan menunaikan sesuatu). Jika diperhatikan lebih cermat maka legenda Ikan Bungo berkaitan dengan tanggung jawab yang dilandasi perasaan malu jika tidak menunaikan tanggung jawabnya. Harkat dan martabatnya akan turun sehingga segala cara dilakukan untuk memenuhi janjinya. Hal ini tergambarkan dalam kutipan cerita.

"Topanggalung dan dengan segenap kemampuan dan kekuatannya sebagai seorang kesatria diangkatnya pedang sambil berkata "Ini adalah bentuk penghinaan sekaligus penghianatan yang harus dibalas setimpal, sungguh aku tak merelakan adikku diperlakukan demikian tanpa izin penguasa negeri dan rakyatku, maka pedang ini akan membuat mereka binasa sampai adikku dapat kubawa kembali".

(JT, 2011)

Berdasarkan data tersebut kita dapat mengamati betapa marahnya Topanggalung saat adiknya diculik, dan Ia rela membunuh apapun yang dijumpai di jalan saat mencari adiknya. Dia merasa itu sebagai tanggung jawab sekaligus penghinaan yang amat sangat sekaligus merupakan tindakan penghianatan yang harus dibalas setimpal.

Apa yang dilakukan Topanggaung bukan semata mata karena nafsu ataupun amarah belaka, namun terlebih dari rasa sayangnya terhadap adiknya yang diambil tanpa pemberitahuan sebelumnya. Hal tersebut yang mendasari kelakuan Topanggalung sehingga berubah drastis dari sifat baiknya yang disegani oleh masyarakat. Hal ini dapat dilihat dari kutipan berikut.
"Topanggalung sangat menyayangi adiknya Becce Koro. Mereka berkembang dalam kehidupan yang damai dan penuh kasih sayang, diasuh orang-orang istana. Topanggalung tumbuh sebagai pemuda yang tangkas dan memiliki keberanian yang luar biasa. Hal ini menimbulkan rasa segan yang diiringi rasa hormat dan tunduk pada kebesaran Toppanggalung,"

(JT, 2011)

\section{Hidup Selaras dengan Alam}

Hubungan manusia dan alam terkait dengan perilaku manusia dengan alam. Sikap Toppanggalung terhadap Ikan Bungo adalah salah satu bukti bahwa tokoh Toppanggalung ingin hidup selaras dengan alam. Ikan Bungo dengan cemas mengembalikan adik Toppanggalung walaupun niat awalnya bukan untuk mencelakai. Atas keberanian Ikan Bungo, Toppanggalung berjanji tidak akan mencelakai Ikan Bungo. Janji Toppanggalung kepada Ikan Bungo terdapat pada data berikut.

"Dengan sikap kesatria spontan didekatkannya pandangan pada ikan Bungo dan dengan penuh hormat dielusnya ikan Bungo, " Hari ini telah kalian kembalikan martabat dan kedaulatan rakyat dan negeriku, maka aku sungguh gembira kalian melakukannya, hari ini kupersaksikan pada langit dan bumi takkan ada dari keturunanku yang akan mencelakaimu. Kelak pun kalian terjaga, dimana apabila diantara anak cucuku ada yang menyentuh, menyakiti apalagi sampai memakan, maka mereka akan mendapat balasan yang setimpal dari para To ri salo"."(JT,2011).

Sebagai seorang yang terhormat Topanggalung memberi balasan kepada Ikan Bungo sebuah janji yang tidak pernah terpikirkan sebelumnya.

Sampai pada masa sekarang ini, janji dari Topanggalung tersebut masih saja dilaksanakan oleh cucu cicitnya yakni tidak memakan Ikan Bungo sebagai penghargaan terbesar yang diberikan kepada mahluk yang telah mengembalikan adik kesayangannya. Walaupun secara umum kita dapat menafsirkan bahwa setiap kebaikan pasti akan dibalas dengan kebaikan pula. 


\section{Adil dengan Alam}

Sikap adil dengan alam juga terdapat pada kutipan dalam legenda Ikan Bungo

"Namun tidak ada yang tahu dan menyadari bahwa jauh di bawah permukaan air (sungai) terdapat suatu kegiatan lainnya. Air sungai yang tenang ternyata menyimpan kesibukan yang sama. Tersebutlah kerajaan To Risalo (buaya berjari-jari lima yang dipercaya merupakan jelmaan manusia) sebagai penguasa sungai turut mempersiapkan upacara meriah bagi sang putri. Para To Risalo bermaksud mengupacarakan sang putri di kerajaan mereka sebagai salah satu bentuk kecintaan mereka pada penguasa yang selama ini turut memberinya kehidupan dan kedamaian."(JT, 2011).

Niat dari To Risalo sangatlah mulia, yakni ingin membalas kebaikan penguasa sungai yakni Toppanggalung dengan mengambil adiknya Becce Koro dan membuat acara yang meriah untuknya. Namun, keluarga mengira adik mereka diculik sehingga membuat para anggota keluarga marah, dan saudaranya Topanggalung dengan keberanian sebagai seorang kesatria pergi mencari adiknya tersebut. Di dalam kisah diceritakan bahwa Topanggalung membunuh binatang apapun yang ditemuinya di sungai sebelum adiknya kembali ke rumah. Sehingga para penghuni sungai menjadi takut dan bersembunyi di dasar sungai. Kemarahan Toppanggalung bukan berarti ia tidak adil dengan alam, bukti keadilannya adalah dengan berdamai melalui sumpahnya setelah mengetahui motif dari hilangnya sang adik.

\section{Musyawarah dan Mufakat}

Musyawarah dan mufakat juga dilakukan oleh To Risalo untuk mengembalikan sang putri. Berdasarkan hasil musyawarah dan mufakat, maka terpilihlah Ikan Bungo yang dengan rasa takut bertemu dengan Topanggalung, tidakan Ikan Bungo yang berani semata-mata demi kedamaian.

"Di permukaan sungai Topanggalung menantikan kedatangan Becce Koro adik kesayangannya, dan ketika sekumpulan ikan Bungo menampakkan diri bersamaan dengan pemunculan sang putri, wajah Topanggalung berubah senang. Dan dengan sikap kesatria spontan didekatkannya pandangan pada ikan Bungo dan dengan penuh hormat dielusnya ikan Bungo, " Hari ini telah kalian kembalikan martabat dan kedaulatan rakyat dan negeriku, maka aku sungguh gembira kalian melakukannya, hari ini kupersaksikan pada langit dan bumi takkan ada dari keturunanku yang akan mencelakaimu. Kelak pun kalian terjaga, dimana apabila diantara anak cucuku ada yang menyentuh, menyakiti apalagi sampai memakan, maka mereka akan mendapat balasan yang setimpal dari para To ri salo". Setelah mendengarkan sumpah Topanggalung, ikan Bungo menghormat meninggalkan Toppanggalung dan Becce Koro. Tak hentihentinya ikan bungo bersyukur atas apa yang didengarnya, setidaknya mereka mendapatkan keyakinan bahwa setiap kebaikan akan mendapat balasannya, hal yang sama jika mereka melakukan sebaliknya dan hubungan ini bisa muncul pada wujud-wujud yang tidak selalu harus sama.”(JT, 2011)

Kutipan di atas, mengisahkan sumpah Topanggalung kepada ikan Bungo dan itu berlaku kepada setiap keturunannya kelak secara turun temurun. Berdasarkan data tersebut jelas bahwa rentetan alur cerita dikisahkan mulai dari awal perkenalan tokoh hingga muncul masalah dari tempat di mana Topanggalung tinggal bersama keluarganya. Selanjutnya, dikisahkan bahwa Topanggalung memiliki saudari yang sangat ia sayangi sampai saudarinya tersebut diambil tanpa sepengetahuannya oleh para penghuni sungai. Kemudian dilanjutkan dengan meledaknya amarah sang tokoh utama atau Topanggalung saat mengetahui adiknya hilang dan ia bersama rombongannya membunuh semua mahluk sungai yang ditemuinya. Setelah itu muncullah Ikan Bungo yang dengan senang hati bersedia membawa kembali adik Topanggalung yaitu Becce Koro. Hingga tibalah pada saat Topanggalung mengikrarkan sumpahnya bahwa ia beserta keturunannya tidak akan pernah 
menyentuh atau memakan Ikan Bungo semasa hidupnya dan sumpahnya ini berlaku untuk selama-lamanya atau bersifat kekal abadi.

\section{Integritas Moral}

"Akibat kekacauaan yang terjadi, para penghuni sungai mencari selamat, mereka berlari menjauh meninggalkan daerah kekuasaan Topanggalung menghindari maut. Namun amarah Topanggalung sudah tak terbendung, sepanjang sungai yang dilaluinya menjadi arena maut bagi penghuninya. Dan pada akhirnya ketika berada di sungai yang berhubungan dengan Teluk Bone, melalui perwaliannya To ri salo menemui Toppanggalung " Wahai tuanku, kami telah khilaf atas kegembiraan kami, berhentilah membunuh para penghuni sungai, kami berjanji akan mengembalikan Putri Becce Koro ke hadapan tuanku" pintanya. Topanggalung dengan menahan amarahnya memberi kesempatan pada To risalo " ini adalah kesempatanmu, maka kembalikanlah adikku atau seluruh penghuni sungai takkan mendapatkan kebebasan" ancamnya. Maka turunlah utusan To risalo mejemput sang putri untuk dapat dikembalikan ke daratan."'(JT,2011)

Berdasarkan data tersebut, sosok penakut dari To Risalo dijelaskan bahwa To risalo tidak berani menemui Topanggalung dan hanya mengutus perwalian untuk meminta maaf kepada Topanggalung. Hal inilah yang menjadi bahan rujukan untuk menganalisis watak tokoh To risalo ini. Selanjutnya dalam kisah yang diceritakan Ikan Bungo memiliki integritas moral yang tinggi. Kerelaan Ikan Bungo untuk menjaga kedamaian dengan memberanikan diri bertemu Toppanggalung meskipun nyawanya terancam.

\section{SIMPULAN}

Berdasarkan hasil penelitian ekologi sastra terkait hubungan timbal balik manusia dan alam dalam legenda Ikan Bungo terdapat perilaku manusia (tokoh) ketika memperlakukan alam. Hubungan ini dapat menjadi pembelajaran bagi kehidupan manusia. Hubungan timbal balik manusia dan alam dalam legenda Ikan Bungo terdiri dari tanggung jawab, hidup selaras dengan alam, adil dengan alam, musyawarah dan mufakat, dan integritas moral.

\section{REFERENSI}

Andriyani Noni, Alber. 2019. Dongeng Masyarakat Kelurahan Telayap Kecamatan Pelalawan Kabupaten Pelalawan Provinsi Riau Dalam Kajian Sastra Ekologis. Jurnal Geram (Gerakan Aktif Menulis), Vol 7, Nomor 2.

Adriyani Noni, Wilda. 2019. Kritik Sastra Ekologiis Terhadap Novel-Novel Terbaru Indonesia. Jurnal Geram (Gerakan aktif Menulis) Vol. 7 No. 1.

Danandjaja, James. 2007. Folkror Indonesia, Ilmu Gosip, Dongeng dan Lain-Lain. Jakarta: Grafity

Edi Subroto, D. 2007. Pengantar Metode Penelitian Linguistik Struktural. Surakarta: Universitas Sebelas Maret Press.

Endraswara, Suwardi. 2018. Metodologi Penelitian Ekologi Sastra (Konsep, Langkah, dan Penerapan).Yogyakarta: CAPS

Ferdan, Agtasia. 2019. Etika Lingkungan dalam Novel Bilangan Fu Karya Ayu Utami dan Implikasinya pada Pembelajaran Sastra di Sekolah.

Hutomo, S. 1991. Mutiara Yang Terlupakan. Surabaya: Himpunan Sarjana Kesusastraan Indonesia, HISKIKomisariat Jawa Timur.

Koentjaraningrat. 2009. Pengantar Ilmu Antropologi Sastra. Jakarta: Rineka Cipta.

Krisdayani, Lisa dkk. 2019. Eksplorasi Legenda Selang Pangeran Sebagai Bahan Ajar Bahasa Indonesia. Jurnal Basa Taka Universitas Balikpapan.

Nurgiyantoro, Burhan. 2013. Teori Pengkajian

Fiksi. Yogyakarta; Gajah Mada University Press.

Rusyana, dkk. 2000. Prosa Tradisional: Pengertian, Klasifikasi, dan Teks. Jakarta: Pusat Bahasa.

Tjandring, Junaedi, 2011. Sumpah 
Topanggalung. http://junaeditjanring.blogspot.com/2011 /11/sumpah-topanggalung.html. diakses tanggal 1 Februari 2019.

Solichin, Moh Badrus. 2019. Ekofeminisme dalam Novel Tentang Kamu Karya Tere Liye. Jurnal Semiotika No.1 Volume 19 Hal.41-50.

Sudikan, Setya Yuwana. 2016. Ekologi Sastra. Lamongan: CV Pustaka Ilalang Group.

Sugiyono, Metode Penelitian Pendidikan Pendekatan Kuantitatif, Kualitatif Dan $R \& D$. Bandung: Alfabeta.

Supriyadi, dkk. Makna Budaya dan Nilai Pendidikan Karakter dalam Syair Ikan Terubuk. Jurnal Geram (Gerakan Aktif Menulis), Vol. 8, No. 2.

Taum, Yoseph Yapi. 2011. Studi Sastra Lisan. Yogyakarta: Lamalera.

Widayati, Ulfa. 2018. Representasi Budaya Masyarakat Dayak Meratus dalam Novel Palas Karya Aliman Syahrani dan Implikasinya Bagi Pendidikan Karakter Siswa SMA (Kajian Etnoekologi Sastra). Tesis

Wiyatmi. 2006. Pengantar Kajian Sastra. Yogyakarta; Pustaka Book Publisher. 